\title{
NOTA SOBRE UN SONETO DE QUEVEDO
}

\author{
Piedad Bolaños Donoso \\ Universidad de Sevilla
}

\author{
"La enfermedad aguda \\ se oponía arrogante: \\ mas la salud venciendo \\ victoriosa se aplaude"1
}

A Mercedes de los Reyes Peña

\begin{abstract}
Dña. Mercedes Agulló y Cobo en la edición de su último libro titulado $A$ vueltas con el autor del Lazarillo ${ }^{2}$ escribe en la primera página, como cita personal: "Ningún hallazgo es una casualidad". Y es cierto. Todo hallazgo es fruto del trabajo y constancia del investigador, ese ser extraño que en los tiempos que corren (“... en la época de los ordenadores, las imágenes, las digitalizaciones, la facilidad para tener a golpe de teclado casi todo...”- - en palabras de Pablo Jauralde ${ }^{3}$-) todavía invierte su tiempo en exhumar los manuscritos (de archivos o de bibliotecas) para acrecentar el saber universal.

La conjunción de este rara avis que es el investigador y la excelente labor que tantas bibliotecas están haciendo al exhumar sus fondos, digitalizarlos y colgarlos en la red ${ }^{4}$ para que puedan ser consultados por el mayor número de curiosos (que no de 'investigadores'), ha hecho posible que podamos conocer esta otra versión de un soneto de Quevedo que voy a presentarles.

Todo empieza con la noticia que suscita la publicación de otro libro de Quevedo: Poesía inédita. Atribuciones del manuscrito de Évora ${ }^{5}$ y el hecho que se recoja en él, con el no 24, el soneto Descripción de la hermosura. Y como bien comenta el doctor Jauralde, prologuista también del citado libro, al no entregar Quevedo

1 Coloquio à la restauración de la salud de cierta Sra. de Sevilla después de seis meses de enfermedad mui prolongada. Mss 332/95 de la Biblioteca Universitaria de Sevilla, f. 147r.

2 Con el testamento y el inventario de Don Diego Hurtado de Mendoza. Prólogo de Pablo Jauralde. Madrid, Ed. Calambur. Biblioteca Literae, 2010.

3 A vueltas con el Lazarillo..., op. cit. p. 11.

${ }^{4}$ Esta es la responsabilidad que D. Eduardo Peñalver tiene en la Biblioteca Universitaria de Sevilla como encargado de la Sección de libros antiguos. Le agradezco su generosidad y curiosidad.

5 Francisco de Quevedo, Poesía inédita. Atribuciones del manuscrito de Évora. Ed. de María Hernández. Prólogo de Pablo Jauralde, Barcelona, Ed. Libros del Silencio, S.L., 2010.
\end{abstract}


personalmente a la imprenta sus versos y al ser admirado por muchos, generó muchas imitaciones ${ }^{6}$. Es cierto que fue imitado por muchos, como dan fe los manuscritos en donde se recoge una versión de este soneto $;$ y también es posible que otra u otras versiones se hayan perdido, por lo que jamás llegaran a nuestro conocimiento.

De entre ésas que se perdieron, sin embargo, tenemos la fortuna de conservar una copia en un manuscrito del siglo XVIII que, de forma anónima, pasó a engrosar el volumen que configuró el P. Fr. Fernando Joseph de los Dolores (murió en Sevilla el 29 de octubre de 1795), y al que rotuló con el curioso nombre de $A$ lo que saliere. Las pocas noticias que del copista sabemos se deben a Fr. Tomás de S. Rafael, el cual escribió una "Advertencia" (colocada en la primera página del libro), cumpliendo el mandato de su Superior, una vez muerto el padre Fernando, para que en la posteridad los lectores supieran a quien se debía ese trabajo de "copia" que el lector encontraría entre los fondos de la Biblioteca del Centro. No es que el autor del trabajo en cuestión fuera un dechado de perfecciones a ojos de su compañero de orden, pero de lo que sí estuvo seguro es que —dice-: "...puede asegurarse que fue fidelisimo en copiar, y que jamas intentó en sus traslados [...] faltar à la verdad, porque su nativo candor, su virtud y su deseo de hacerse útil, no se lo permitían"8.

Sostengo que hubo de copiar fielmente de algún texto, hoy perdido, pues, de los hasta ahora conocidos por los especialistas quevedianos, no coincide con ninguno de ellos, como se podrá apreciar en las variantes que acompañan la edición del citado soneto. He aquí el texto de la copia realizada en el siglo XVIII9:

"Un Galan picado de los desprecios de una Dama, à quien pretendia, se despica con el consiguiente ${ }^{10}$

Soneto

6 Poesía inédita..., op. cit., p. 15.

7 Según María Hernández, son los siguientes (a los que reconocemos con la letra mayúscula que yo he destinado para presentar las variantes): $\mathrm{ms}$. de Évora $=E ;$ ms. $3912 \mathrm{BNE}=A$; ms. 3913 $\mathrm{BNE}=B ;$ ms. $3922 \mathrm{BNE}=C ;$ ms. $4052 \mathrm{BNE}=D ; \mathrm{ms} .4067 \mathrm{BNE}=F ;$ ms. $20620 \mathrm{BNE}=G . \mathrm{E} 1$ texto que yo presento le ha denominado $P$.

8 Mss. 332/95 de la Biblioteca Universitaria de Sevilla. En 4º, pergamino, con 307 hojas. Estas palabras proceden de la "Advertencia" (s.f.). La mayor parte de los traslados que hizo son de temática religiosa, como puede comprobarse al contenido del libro por estar digitalizado y colgado en la red.

9 Ff. 306v-307r.

10 Un Galan picado de los desprecios de una Dama, à quien pretendia, se despica con el consiguiente Soneto $P$ / Descripción de la hermosura $E$ / Soneto al amor $A$ / Otro $B$ / Soneto. De D. Fran[cis]co Candamo. Desengaño de una hermosura $C$ / Para desengaño de los hombres $D$ / Soneto $F$ / Soneto a el desprecio de amor $G$. 
Piojo ${ }^{11}$ anida $^{12}$ el pelo ${ }^{13}$ mas pulido ${ }^{14}$, lagaña ${ }^{15}$ cria $^{16}$ el ojo más vistoso ${ }^{17}$, y en ${ }^{18}$ la nariz del rostro mas hermoso ${ }^{19}$ el moco verdinegro ${ }^{20}$ està escondido ${ }^{21}$.

E1 labio ${ }^{22}$ de coral $^{23}$ mas encendido ${ }^{24}$ echa un regueldo ${ }^{25}$ sucio, y asqueroso ${ }^{26}$ la mano de cristal $^{27}$ es mui ${ }^{28}$ forzoso, que al culo de su Dueño haya servido ${ }^{29}$.

A la hermosa le vaja, y à la fea ${ }^{30}$; el mejor Pollo de este mundo mea ${ }^{31}$ : dos dedos junto al culo vive, y mora ${ }^{32}$.

$\mathrm{Si}$ aquesta es la beldad que me enamora ${ }^{33}$, y todo culo caga mierda pura ${ }^{34}$, cagome en ti, y en toda tu hermosura ${ }^{35}$.

11 Piojo $P$ / Piojos EA B C D F G.

12 Anida $P$ / crìa $E A B C D F G$.

13 Pelo $P$ / cabello E A B CDFG.

14 Pulido $P$ / dorado $E A B C D F G$.

15 Lagaña $P$ / lagañas $E A B F G$ / y lagañas $C$ / y lagaña $D$.

16 Cria $P /$ hace $E B D F G /$ tiene $A /$ omisit $C$.

17 Vistoso $P E A B D F G /$ hermoso $C$.

$18 \mathrm{Y}$ en $P A B D F G$ / en $E C$.

19 Hermoso $P E A B D F G$ / ayroso $C$.

20 Moco verdinegro $P A B D F /$ asqueroso moco $E$ / verdinegro moco $C$ / sucio i verde moqo $G$.

21 Escondido $P$ / enredado $E$ / encerrado $A B C D F G$.

22 El labio $P A B D F /$ la boca $E C /$ y el labio $G$.

23 De coral $P A$ / de clavel $E C G$ / del clavel $B F /$ del coral $D$.

24 Encendido $P$ / encarnado $E A B C D F G$.

25 Echa un regueldo $\mathrm{P} /$ tal vez regüelda $\mathrm{E} \mathrm{A} \mathrm{B} \mathrm{C} \mathrm{F} \mathrm{G} \mathrm{/} \mathrm{echa} \mathrm{resuello} \mathrm{D.}$

26 Sucio y asqueroso $P D /$ a hálito fatigoso $E$ / a hálito y asqueroso $A G$ / mustio y asqueroso $B F /$ hediondo y asqueroso $C$.

27 La mano de cristal $P$ / y la mano más blanca $E A B C F G$ / y la más blanca mano $D$.

28 Mui $P E A B D F G /$ omisit $C$.

29 Servido $P$ / llegado $E A B C F G$ / tocado $D$.

30 A la hermosa le baja y à la fea $P / E l$ mejor papo de la dama mea $E$ / El más limpo de este mundo mea $A$ / El mejor coño de este mundo mea $B G / \mathrm{E} 1$ mejor chesmu de este mundo mea $C$ / A la blanca le baja y a la fea $D$ / El mejor zaraguelle de este mundo mea $F$.

31 El mejor Pollo de este mundo mea $P$ / y [a] dos dedos del culo vive y mora $E A B C F G$ / el mejor papo de este mundo mea $D$.

32 Dos dedos junto al culo vive, y mora $P$ / y cuando aquesta caga, es mierda pura $E$ / caga el mas limpio culo mierda pura $A B F$ / este caga por fuerza mierda pura $C /$ y dos dedos del culo, vive y mora $D$ / a la ermosura le baja i a la fea $G$.

$33 \mathrm{Si}$ aquesta es la beldad que me enamora $P$ / Esto tiene la hermosura y más la fea $E$ / A la hermosura le baxa y a la fea $A B F /$ Si la mujer que tanto se desea $C$ / Si aqueste es el amor que te enamora $D$ / que el culo quando caga es mierda pura $G$.

$34 \mathrm{Y}$ todo culo caga mierda pura $P D$ / veis aquí el muladar que os enamora $E$ / si este es el amor que me enamora $A$ / este es el muladar que os enamora $B G$ / es este muladar que se enamora $C /$ ¿y este es el muladar que os enamora? $F$.

35 Cagome en ti,y en toda tu hermosura $P$ / cágome en el Amor y en su hermosura $E G$ / cagome en este amor y en su hermosura $A$ / cagome en el amor y en la hermosura $B C F /$ cagome en él y toda su hermosura $D$. 
Con esta 'nota' quevediana no pretendo nada más que llamar la atención sobre la copia referida para que no quede como anónima, sino que el curioso sepa a quién corresponde la idea original del trabajo (¿quién nos podría negar que no fuera ésta una de las ramas más cercanas a la primera versión que realizara el autor?) y hacer ver a mis alumnos (como así lo he hecho) que el siglo XVIII español, a pesar de no haber sido el que más 'ingenios' aportara al campo de la creación literaria, fue una excelente época trasmisora de buena parte de textos de los siglos precedentes que, sin la dedicación y entusiasmo de esos hombres, los hubiéramos perdido para siempre.

Nombre del autor: Piedad Bolaños Donoso

Dirección-e: piedad@us.es

Dirección postal: Dpto. de Literatura Española, Universidad de Sevilla, Facultad de Filología, C/ Palos de la Frontera, s/n, 41004, Sevilla

Fecha de recepción: 08/10/2011

Fecha de aceptación: 08/10/2011 